\title{
A GREEN APPROACH FOR THE SYNTHESIS OF DRUG DELIVERY SYSTEM, MESOPOROUS SILICA GRAFTED ACRYLAMIDE - $\beta$ - CYCLODEXTRIN COMPOSITE, FOR THE CONTROLLED RELEASE OF CURCUMIN
}

\author{
MANOHAR D MULLASSERY*, NOELINE B FERNANDEZ, SURYA R, DIANA THOMAS
}

Department of Chemistry, Fatima Mata National College, Kollam - 691 001, Kerala, India. Email: mdmullassery@gmail.com Received: 18 April 2018, Revised and Accepted: 02 June 2018

\section{ABSTRACT}

Objective: The scope of the present study was the preparation and characterization of a novel composite acrylamide $\beta$-cyclodextrin grafted 3-aminopropyltriethoxysilane bentonite (AMCD-g-APSB), for the controlled delivery of curcumin (CUR).

Methods: AMCD-g-APSB, was synthesized by solvent-free conditions using microwave irradiation. The structure and surface morphology of the composite was established using Fourier transform infrared spectroscopy, X-ray diffraction, scanning electron microscopy, thermal analysis, etc.

Results: The swelling percentage of the composite depends on both time and $\mathrm{pH}$ of the medium. The maximum swelling of the composite occurred at a $\mathrm{pH}$ of 7.4. The maximum drug encapsulation was occurring at a $\mathrm{pH} 3$. About $96.5 \%$ of drug was loaded at $\mathrm{pH} 3$. In vitro biocompatibility study was performed, and the result showed good biocompatibility of the composite in the concentration range $2.5-50 \mu \mathrm{g} / \mathrm{ml}$.

Conclusions: Drug delivery study of the composite proved that CUR could be successfully released in a controlled manner in the colon without much loses of the drug in the stomach.

Keywords: Bentonite, Controlled release, Curcumin, Kinetics.

(C) 2018 The Authors. Published by Innovare Academic Sciences Pvt Ltd. This is an open access article under the CC BY license (http://creativecommons. org/licenses/by/4. 0/) DOI: http://dx.doi.org/10.22159/ajpcr.2018.v11i9.26769

\section{INTRODUCTION}

Cancer is a group of disease involving abnormal cell growth with the potential to spread to other parts of the body. Over 100 types of cancer affect human. According to $\mathrm{WHO}$, cancer is the second leading cause of death globally. Chemotherapy is one of the major treatments of cancer. However, chemotherapy has many limitations such as uncontrolled drug toxicity, undesirable side effects, etc. Researchers over the last two decades concentrated on the investigation studies of anticancerous drugs with comparatively low side effects. Curcumin (CUR) is identified as one of the natural compounds with significant efficiency and less toxic. CUR is a bioactive component of the food additive Curcuma Longa which is widely used in Asian countries. The number of cancer patients in south Asian countries are relatively low, this may due to the more consumption of turmeric as dietaries $[1,2]$.

The bright yellow-orange color of turmeric is due to the fat-soluble polyphenolic pigments known as curcuminoids. CUR is the principal curcuminoid found in turmeric. The chemical formulae and molecular weight of CUR are $\mathrm{C}_{21} \mathrm{H}_{20} \mathrm{O}_{6}$ and $368.38 \mathrm{~g} / \mathrm{mol}$ respectively. IUPAC name is (1E, 6E)-1,7-bis(4-hydroxy-3-methoxyphenyl)-1,6-heptadiene3,5-dione. CUR has two aromatic ring systems containing o-methoxy phenolic groups, linked with a seven carbon linker consisting of an $\alpha$, $\beta$ - unsaturated and $\beta$-diketone moiety, as shown in Fig. 1. CUR undergoes keto-enol tautomerism, in nonpolar and moderately polar solvent, enol form of CUR is more stable to exist than the ketoform [2]. Preclinical and clinical studies show that CUR exerts anti- inflammatory, antioxidant, anticancerous, neuroprotective, and antidiabetic activities. Many studies were reported on the anticancerous activity of CUR against colon, liver, pancreatic, ovarian, and breast cancers $[3,4]$.

CUR has some important drawbacks such as its low water solubility, rapid hydrolysis under high alkaline conditions, and susceptibility to photochemical degradation. It also exhibits poor absorption, rapid metabolism, and low bioavailability. These limitations can be overcome by the use of a biocompatible and novel drug carrier system for the effective encapsulation and successive release of CUR to the targeted site without losing its anticancerous activity [5].

The mesoporous silica materials can be used as a potential drug carrier system for the controlled and targeted drug delivery. Hence, many studies have been reported in porous silica-based materials as drug carriers [6-8]. Table 1 shows different kinds of modified mesoporous systems used as drug delivery systems. Mesoporous materials have tunable pore size; it can change its pore size from 2 to $50 \mathrm{~nm}$. Hence, this material can be used as a better drug carrier system for different kinds of bioactive materials of with variable size [9].

Montmorillonite belongs to the smectite group, composed of silica tetrahedral sheets layered between alumina octahedral sheets at the ratio of 2:1, respectively. The mineral composition of bentonite is quite variable depending on its origin. In general, sodium montmorillonite represents the main components in these clays (up to $80 \%$ by weight). However, for the development of bentonite-based controlled release formulations, their properties must be needed to modify for improving their affinity for bioactive drug molecules. Intercalation of polymer matrix onto clay scaffold is one of the treatment techniques is gaining attention, as the composite hydrogel has got the combined advantages of biodegradability of polymer matrix and tunable pore size of the mesoporous silica.

In the present study, a biocompatible $\mathrm{pH}$-sensitive composite was prepared by the grafted copolymerization of $\beta$-cyclodextrin - acrylamide (AMCD) intercalated by the modified 3-Aminopropyltriethoxysilane bentonite (APSB) for the controlled release of CUR [16]. During the intercalation, a calculated amount of ethylene glycol dimethacrylate (EGDMA) was used a crosslinker agent because it can form stable networks by withstanding wide range of $\mathrm{pH}$ and temperature [17]. 
Table 1: List of different kinds of modified mesoporous silica materials as drug delivery system

\begin{tabular}{lll}
\hline Drug delivery system & Drug & Reference \\
\hline Montmorillonite-poly lactic-coglycidic acid composite & Insulin & {$[10]$} \\
Amino functionalized mesoporous nanomaterial & 5 -Flurouracil & {$[11]$} \\
Alginate encapsulated mesoporous silica & Indomethacin & {$[12]$} \\
Amine functionalized cubic mesoporous silica material & CUR & {$[13]$} \\
3-aminopropyltriethoxysilane modified mesoporous silica material & CUR & {$[14]$} \\
Chitosan mesoporous silica material & CUR & {$[2]$} \\
Carboxymethyl cellulose grafted mesoporous silica material & CUR & {$[15]$} \\
Present study & CUR & \\
\hline
\end{tabular}

CUR: Curcumin<smiles>COc1cc(/C=C/C(=O)CC(=O)/C=C/c2ccc(O)c(OC)c2)ccc1O</smiles>

Fig. 1: Structure of curcumin

The intercalated composite of the natural clay (bentonite) with the polysaccharides could retain its properties such as biodegradability, non-toxicity, swelling, behavior, etc. [18]. The grafted composite of clays with the hydrogel can act as a potential drug delivery system $[19,20]$.

\section{MATERIALS AND METHODS}

\section{Materials}

The bentonite clay was procured from Ashapura Clay Mines (Gujarat, India). $\beta$-cyclodextrin (CD), EGDMA, CUR were purchased from Tokyo Chemical Industry (Japan). AM was received from Merck Life Science Pvt. Ltd (India). Ceric ammonium nitrate (CAN) was obtained from Merck Specialities Pvt. Ltd (India). Acetone and $\alpha, \alpha$-azobisisobutyronitrile (AIBN) and 3-aminopropyl triethoxysilane were procured from Spectrochem Pvt., Ltd (India). Dulbecco's Modified Eagle's Medium (DMEM), 3-(4, 5-dimethylthiazol-2-yl)-2, and 5-diphenyltetrazolium bromide (MTT) were purchased from Himedia (Mumbai, India). U87MG glioma cell line was provided by NCCS (Pune, India). The pH of the medium was adjusted using phosphate and citrate buffer. Distilled water with specific conductivity $<1 \mu \mathrm{S} / \mathrm{cm}$ was used throughout the study. The stock solution of CUR was prepared in ethanol. CUR solution was freshly prepared for each and every day use.

\section{Synthesis of the drug delivery system (AMCD-g-APSB) involves the following steps}

\section{Preparation of APSB}

About $10 \mathrm{~g}$ of powdered bentonite was dispersed in excess of $1 \mathrm{M}$ $\mathrm{NaCl}$ solution and kept for $24 \mathrm{~h}$. The solution was centrifuged and washed with distilled water till it was completely free from chloride ions. After the removal of chloride ions, the clay was dried at $80^{\circ} \mathrm{C}$ and grained to powder. About $5.0 \mathrm{~g}$ of Na-B was dried at $60^{\circ} \mathrm{C}$ for $24 \mathrm{~h}$ and dispersed in $100 \mathrm{ml}$ of methanol. Separately, a solution with $5 \mathrm{~g}$ of 3-aminopropyltriethoxysilane (pur) was dissolved in $100 \mathrm{ml}$ solvent. This solution was added to the dispersion containing Na-Bentonite [21]. The dispersion was stirred at $50^{\circ} \mathrm{C}$ under magnetic stirring for $72 \mathrm{~h}$. After complete stirring, the product was centrifuged and washed with distilled water, dried at $80^{\circ} \mathrm{C}$ and grained to fine powder.

\section{Solvent-free synthesis of $A M C D$}

The grafted copolymer derived from AAm (pure) and $\beta$-CD (pure) was prepared by microwave assisted, free radical-induced polymerization method. About, $1.0 \mathrm{~g} \beta$-CD was dispersed in $120 \mathrm{ml}$ of water and $5 \mathrm{~g}$ of $\mathrm{AM}$ was mixed with $30 \mathrm{ml}$ of water and added to $\beta$-CD-water mixture and stirred for $1 \mathrm{~h} .300 \mathrm{mg}$ of CAN (pure) was dissolved in $30 \mathrm{ml}$ of water and added to the above dispersion [22-25]. The dispersion was

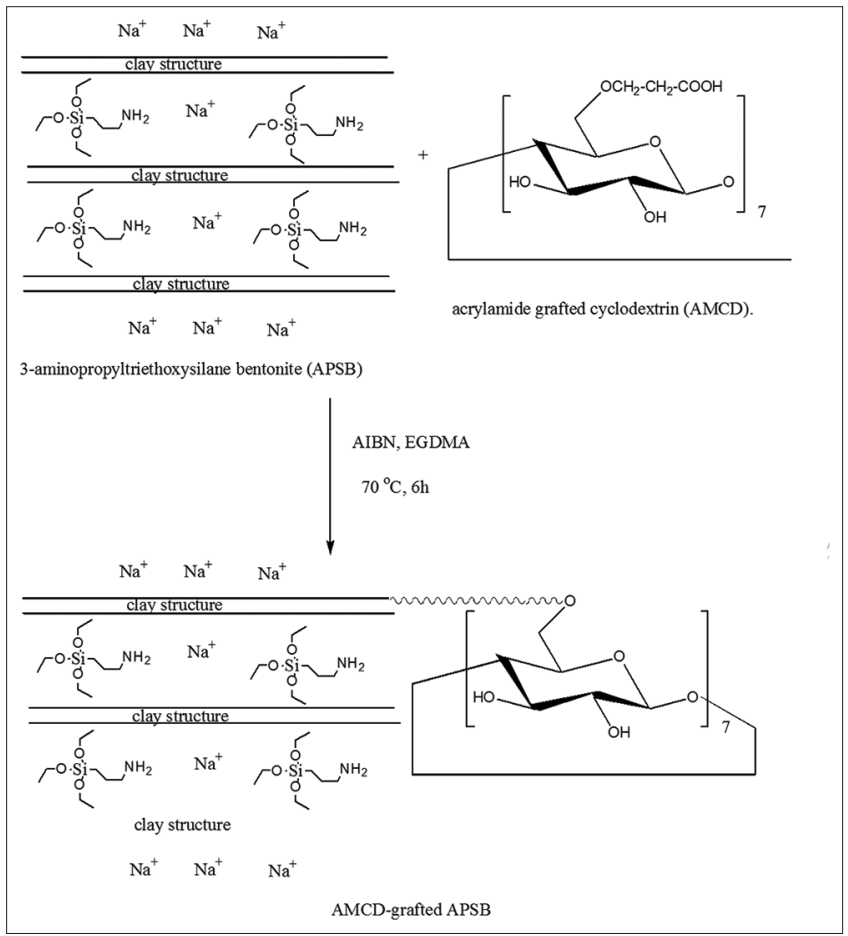

Scheme 1: Preparation of acrylamide $\beta$-cyclodextrin grafted 3-aminopropyltriethoxysilane bentonite

irradiated by microwave for $2 \mathrm{~min}$. It was left for overnight and then precipitated using acetone (pure). The unreacted monomer and other reagents were removed by washing with aqueous ethanol $(30 \%, \mathrm{v} / \mathrm{v})$. The grafted polymer was then dried at $40^{\circ} \mathrm{C}$ to a constant weight and converted to fines.

\section{Preparation of AMCD-grafted-APSB}

The preparation of AMCD-g-APSB was represented in Scheme 1. About $5.0 \mathrm{~g}$ of APSB, $2.5 \mathrm{~g}$ of AMCD, $0.50 \mathrm{~g}$ of EGDMA and $0.04 \mathrm{~g}$ of AIBN were added to a three neck RB flask which was equipped with a magnetic stirrer and a reflux condenser. To the above mixture, $25 \mathrm{ml}$ of methanol was added, and the flask was purged by dry $\mathrm{O}_{2}$ free $\mathrm{N}_{2}$ for $30 \mathrm{~min}$. The mixture was heated at $70^{\circ} \mathrm{C}$ for $5 \mathrm{~h}$ and stirred continuously (1250 rpm). The product obtained was separated by filtration and washed well with distilled water and methanol $(30 \%, v / v)$ to remove the by-products. The product was dried at $60^{\circ} \mathrm{C}$ and kept overnight and ground to an average particle size of $0.095 \mathrm{~mm}$.

\section{Characterization}

The Fourier transform infrared spectroscopy (FTIR) spectral analysis was performed in transmission mode using a Bruker spectrophotometer (Germany). Spectral scanning was done at $4 \mathrm{~cm}^{-1}$ resolutions with 32 scans over spectral range from 400 and $400 \mathrm{~cm}^{-1}$. XRD studies were used to find out the crystallinity of a substance. X-ray diffraction (XRD) measurements were carried out on a Rigaku Geigerflex XRD meter with 
$\mathrm{Ni}$ filtered $\mathrm{Cu} \mathrm{K} \alpha$ radiation at $40 \mathrm{kV}, 20 \mathrm{~mA}$. The thermal analyses were made on a Mettler Toledo Star system under nitrogen atmosphere with a heating rate of $20^{\circ} \mathrm{C} \mathrm{min}{ }^{-1}$. A Philips model XL $30 \mathrm{CP}$ scanning electron microscope (SEM) was used to take micrographs. In this instrument, cryofreezing method was used for taking SEM photographs at $15 \mathrm{kV}$ and $20 \mathrm{kV}$ with a working distance of $6 \mathrm{~mm}$, in which freezed samples were coated with a thin layer of gold to make the surface conductive toward electron beam. The $\mathrm{pH}$ of the medium was measured using a $\mathrm{pH}$ meter (Systronic model $\mu$ 362, India). Absorbance of CUR in the drug carrier was conducted by UV-Visible spectrophotometer (Systronics, India) at $\lambda_{\text {max }}$ of $428 \mathrm{~nm}$.

\section{Swelling studies}

Swelling of drug carrier systems was important in the effective and targeted delivery of drugs. The swelling behavior of the sample was studied as a function of $\mathrm{pH}$ (2 to 9). The $\mathrm{pH}$ of the solution was adjusted by varying concentrations of $\mathrm{NaOH}$ and $\mathrm{HCl}$. The samples were immersed in excess aqueous medium of desired $\mathrm{pH}$ for $10 \mathrm{~h}$ to achieve the equilibrium. The swollen samples were then separated and excess surface adhered water molecules were removed by blotting. It was then dried in an air oven at $50^{\circ} \mathrm{C}$ until there was no change in the dried mass of the sample. The percentage equilibrium water uptake can be calculated as (Equation 1).

Swelling $(\%)=\frac{W_{\text {wet }-W_{d r y}}}{W_{d r y}} \times 100$

\section{Stability study of CUR at different $\mathrm{pH}$ conditions}

The stability study of CUR was carried out at different $\mathrm{pH}$ conditions of $2,4,6,7$, and 8 . A stock solution of CUR was prepared by dissolving about $5 \mathrm{mg}$ of CUR in $100 \mathrm{ml}$ of methanol-distilled water mixture $(60: 40 \mathrm{v} / \mathrm{v})$. Each experiment was carried out in dark conditions, incubated at 37 $\pm 1^{\circ} \mathrm{C}$ in citrate buffer and phosphate buffer. At definite time intervals, $5 \mathrm{ml}$ of the solution was pipetted out, filtered, and measured for the concentration using the UV-visible spectrophotometer (Systronics, India) at $\lambda_{\max }$ of $428 \mathrm{~nm}$

\section{Drug encapsulation efficiency studies}

About $0.1 \mathrm{~g}$ of the composite and CUR solution at an initial concentration of $50 \mathrm{mg} / \mathrm{l}$ were taken in amber-colored stoppered bottle and stirred at $1000 \mathrm{rpm}$ for $6 \mathrm{~h}$. To get the maximum encapsulation, the analysis was carried out at different $\mathrm{pH}$ range of 2-7. The encapsulation study was also repeated for another CUR concentration of $75 \mathrm{mg} / \mathrm{l}$. Along with the encapsulation efficiency study of CUR onto the drug delivery composite AMCD-g-APSB, a comparative study was also done with APSB, a precursor unit of the composite. The percentage of drug encapsulation efficiency was calculated as (Equation 2).

$$
\mathrm{DEE}=\frac{\text { Total Curcumin }- \text { FreeCurcumin }}{\text { TotalCurcumin }} \times 100 \%
$$

\section{In vitro drug release study}

Release study of CUR from AMCD-g-APSB and APSB were investigated on different $\mathrm{pH}$ conditions of $2.4 \pm 0.2,6 \pm 0.2$, and $7.4 \pm 0.2$. About $0.1 \mathrm{~g}$ of CUR-loaded AMCD-g-APSB was put in different $\mathrm{pH}$ of $2.4,6$, and $\mathrm{pH} 7.4$ separately placed on the water bath shaker of constant temperature of $37 \pm 1^{\circ} \mathrm{C}$ rotated at $100 \mathrm{rpm}$. At the specified intervals, about $5 \mathrm{ml}$ of the solution was pipetted out and filtered. The concentration of drug release was measured spectrophotometrically. The release studies were performed thrice and the mean percentage was taken as \pm standard deviation (SD). The cumulative release profile of CUR was calculated and plotted as the percentage of cumulative release against time (Equation 3).

$$
\% \text { of cumulative release }=\frac{\text { Curcumin released }}{\text { Total amount of curcuminloaded }} \times 100
$$

The in vitro release kinetics studies were analyzed using the Peppas kinetic relation (Equation 4).

$$
\frac{M t}{M \infty}=K t^{n}
$$

where $M_{t}$ is the amount of drug released at time $t$ and is the amount of the drug release completely. $\mathrm{k}$ is the rate constant and $\mathrm{n}$ is the diffusion exponential.

\section{Cell viability analysis and cell culture conditions}

U87MG glioma cells were used as an in vitro model for toxicological studies. The U87MG cells were cultured in DMEM under the temperature of $37^{\circ} \mathrm{C}$ and supplemented with $10 \%$ FBS in an atmosphere of $5 \% \mathrm{CO}_{2}$ and a humid atmosphere was maintained. The cells were trypsinized with buffered saline solution containing $0.25 \%$ of trypsin and $0.03 \%$ of EDTA. The cells were placed to a culture plate for $24 \mathrm{~h}$. MTT assay is a colorimetric assay used for the determination of cell proliferation and cytotoxicity, based on the reduction of the yellow-colored watersoluble tetrazolium dye MTT to formazan crystals. Mitochondrial lactate dehydrogenase produced by live cells reduces MTT to insoluble formazan crystals, which on dissolution into an appropriate solvent exhibits purple color, the intensity of which is proportional to the number of viable cells and can be measured spectrophotometrically at $570 \mathrm{~nm}$. Briefly, seeded using a $200 \mu \mathrm{l}$ cell suspension in a 96-well plate at a cell density of 20,000 cells per well without the test agent. Allow the cells to grow for about $12 \mathrm{~h}$. Add appropriate concentrations of the test agent $(2.5 \mu \mathrm{g} / \mathrm{ml}, 5 \mu \mathrm{g} / \mathrm{ml}, 10 \mu \mathrm{g} / \mathrm{ml}, 20 \mu \mathrm{g} / \mathrm{ml}$, and $40 \mu \mathrm{g} / \mathrm{ml})$. Incubate the plate for $24 \mathrm{~h}$ at $37^{\circ} \mathrm{C}$ in a $5 \% \mathrm{CO}_{2}$ atmosphere. After the incubation period, plates are taken from the incubator, and spent media is removed and MTT reagent is added to a final concentration of $0.5 \mathrm{mg} / \mathrm{ml}$ of total volume. Wrap the plate with aluminum foil to avoid exposure to light. Return the plates to the incubator and incubate for $3 \mathrm{~h}$. The MTT reagent is removed and then add $100 \mu \mathrm{l}$ of solubilization solution (DMSO). The absorbance is measured on a spectrophotometer at $570 \mathrm{~nm}$ and $630 \mathrm{~nm}$ is used as a reference wavelength. The cell viability percentage and percentage of cytotoxicity can be calculated by the following equations

Cell viability $\%=\frac{\text { Optical density of test }}{\text { Optical density of controll }} \times 100$

Cytotoxicity $\%=100-$ cell viability $\%$

\section{Statistical analysis}

All the results were expressed as mean \pm SD. Statistical analysis was performed with origin 8.0 (Origin -Lab Corporation, USA).

\section{RESULTS AND DISCUSSION}

\section{Synthesis of the composite and characterization}

Sodium bentonite (NB) was the starting material used in the synthesis of the drug delivery system AMCD-g-APSB. AMCD-g-APSB was formed by the grafting copolymerization of the biocompatible monomer units AMCD and APSB. The grafting synthesis was carried out in the presence of the cross-linking agent EGDMA and the free radical initiator AIBN. The surface of NB was modified by exchanging water molecules with APS in ethanol medium [26]. The water molecules present in the ethanol medium catalyzed the surface silylation of Na-B by APS. Because of the intercalation of the APS, the basal spacing of APSB was increased [27]. The copolymer hydrogel, AMCD can act as a "gate keeper" molecule in which it can be introduced to the tuning pore size of the clay for the effective loading and the controlled release of drug [28-30]. During the synthesis of AMCD from $\beta-C D$ and AAm, CAN was used as the free radical initiator.

The FTIR spectra of NB, APSB, AMCD, AMCD-g-APSB, CUR, and CUR-LAMCD-g-APSB were shown in Fig. 2. A broad absorption band observed 
at $3615 \mathrm{~cm}^{-1}$ of $\mathrm{Na}-\mathrm{B}$ represents stretching vibrations of different $-\mathrm{OH}$ groups present in $\mathrm{Mg}-\mathrm{OH}-\mathrm{Al}, \mathrm{Al}-\mathrm{OH}-\mathrm{Al}$ and $\mathrm{Fe}-\mathrm{OH}-\mathrm{Al}$. A strong peak at $1048 \mathrm{~cm}^{-1}$ showed the $0-\mathrm{Si}-\mathrm{O}$ bending vibration. The peaks at $545 \mathrm{~cm}^{-1}$ and $460 \mathrm{~cm}^{-1}$ represent the bending vibrations of Al-O-Si and Si-O-Si respectively. Another peak at $950 \mathrm{~cm}^{-1}$ corresponds to $\mathrm{Al}-\mathrm{O}-\mathrm{Al}$ bending vibration. The $\mathrm{H}-\mathrm{O}-\mathrm{H}$ bending vibration of water molecules intercalated in the clay mineral was represented by a peak at around $1628 \mathrm{~cm}^{-1}$. In APSB, two bands were observed nearly at 1552 and $1493 \mathrm{~cm}^{-1}$ which can be explained due to the bending vibrations of $\mathrm{N}-\mathrm{H}$ and $\mathrm{CH}_{2}$ group, respectively. Another band at $3010 \mathrm{~cm}^{-1}$ due to the $\mathrm{C}-\mathrm{N}$ stretching and the bands at $2860-2924 \mathrm{~cm}^{-1}$ represent the $\mathrm{C}-\mathrm{H}$ vibrations of amino propyl group. The presence of two bands due to $-\mathrm{NH}$ and $-\mathrm{CH}$ in the spectrum could be considered as an evidence for the intercalation of silane molecules in the clay mineral. After silylation, it can be seen that silane group is present both as covalently bonded to the clay mineral and by hydrogen bonding interaction with intercalated water molecules as evident from the broad band observed in the spectrum of ASPB between $3010-2700 \mathrm{~cm}^{-1}$.

In the FTIR spectrum of AMCD, a characteristic band of ether linkage was found at $1030-1032 \mathrm{~cm}^{-1}$. The band at $1628 \mathrm{~cm}^{-1}$ may be due to the $\mathrm{O}-\mathrm{H}$ bending vibrations. Two prominent bands of Am at 1651 and $1602 \mathrm{~cm}^{-1}$ were due to the presence of C-O stretching and $\mathrm{N}-\mathrm{H}$ bending vibrations of amide group, respectively. An overlap band of $\mathrm{N}-\mathrm{H}$ and $\mathrm{O}-\mathrm{H}$ stretching peak were observed at $3188-3499 \mathrm{~cm}^{-1}$. A shoulder at around $1450 \mathrm{~cm}^{-1}$ (C-N str) and a prominent peak at $1022 \mathrm{~cm}^{-1}$ were observed which resulted from the $\mathrm{CH}-\mathrm{O}-\mathrm{CH}_{2}$ group which occurred during grafting reaction.

In the FTIR of AMCD-g-APSB, a peak of - $\mathrm{CH}-\mathrm{O}-\mathrm{CH}_{2}$ was shifted to lower intensity. A new peak at $1205 \mathrm{~cm}^{-1}$ observed can be attributed to the C-O-O- stretching vibrations of ester linkage formed between $\mathrm{COOH}$ group in the AMCD and the hydroxyl groups of APSB. In the FTIR spectrum of CUR a broad absorption band at $3520 \mathrm{~cm}^{-1}$ was due to phenolic $\mathrm{OH}$ group. The aromatic ring of CUR gave two peaks at 1504 and $1435 \mathrm{~cm}^{-1}$ resulted from $\mathrm{CH}$ bending and $\mathrm{CH}$ stretching vibrations,

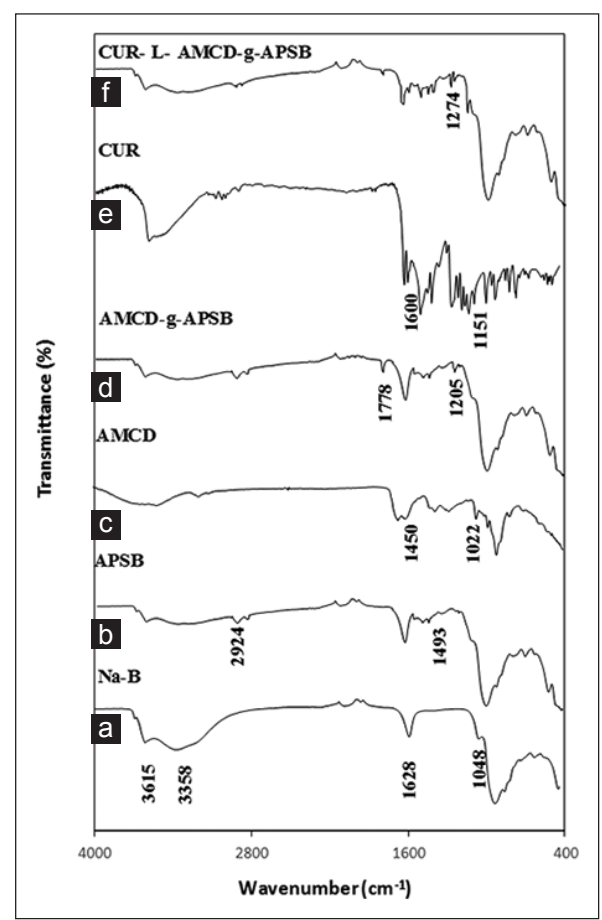

Fig. 2: Fourier transform infrared spectroscopy of (a) Sodium bentonite (b) 3-aminopropyltriethoxysilane bentonite (APSB) (c) acrylamide $\beta$-cyclodextrin (AMCD) (d) AMCD-grafted-APSB (AMCD-g-APSB) (e) curcumin (CUR) and (f) CUR-L-AMCD-g-APSB respectively. Most of the peaks in CUR were retained after loading with DDS showing the effective encapsulation of drug onto composite by weak physical adsorption.

Fig. 3 represents the XRD patterns of NB, APSB, AMCD, AMCD-g-APSB, Cur-L-AMCD-and g-APSB. NB showed a peak at $2 \theta=6.89$ of basal spacing $13.02 \AA$ Af. After silylation, the basal spacing was increased to $d_{001}=21.15 \AA$ which resulted in the lowering of $2 \theta$ value to 4.17 . In APSB, a new peak was appeared [19] which correspond to $d_{002}$ reflection. Compared to the XRD spectrum of NB the increase in basal spacing of APSB by $8.13 \AA$ is an evidence for the successive intercalation of 3-aminopropyltriethoxysilane moiety. The broad peaks in the XRD of AMCD indicate the amorphous behavior of the polymer formed. Successful grafting led to an increase in amorphous nature and the swelling features. In the XRD of AMCD-g-APSB, the peaks of APSB were retained and a broad peak indicated the successful grafting of AMCD on APSB. The XRD pattern of the composite and the drug-loaded composite had no remarkable changes as evident from the Figure.

The TG and DTG curves of NB, APSB, AMCD, AMCD-g-APSB, and CUR-L-AMCD-g-APSB were shown in Fig. 4. For NB dehydration at temperature below $100^{\circ} \mathrm{C}$ was initially observed, which may be due to the elimination of weakly adsorbed water molecules on the edges and in the interlayer space. Similar behavior was also shown by APSB which showed weight loss up to $100^{\circ} \mathrm{C}$. The weight loss of APSB was higher than that of NB possibly due to the presence of intercalated silane molecules. Three distinct mass loss events were observed in the DTG curve of APSB between $240^{\circ} \mathrm{C}$ and $640^{\circ} \mathrm{C}$. These correspond to the loss of silane molecules that were weakly adsorbed by hydrogen bonding, intercalated and chemically bonded to the clay mineral, respectively. The observed initial mass loss at around $80^{\circ} \mathrm{C}$ for AMCD was explained for the presence of moisture, solvents, and unreacted monomers. However, no mass loss occurred at the later stage up to $250^{\circ} \mathrm{C}$. The weight loss at $275^{\circ} \mathrm{C}, 375^{\circ} \mathrm{C}$, and $575^{\circ} \mathrm{C}$ correspond to breaking of rigid polymer network. Compared to AMCD, the composite AMCD-g-APSB was thermally more stable and showed no weight loss after $430^{\circ} \mathrm{C}$.

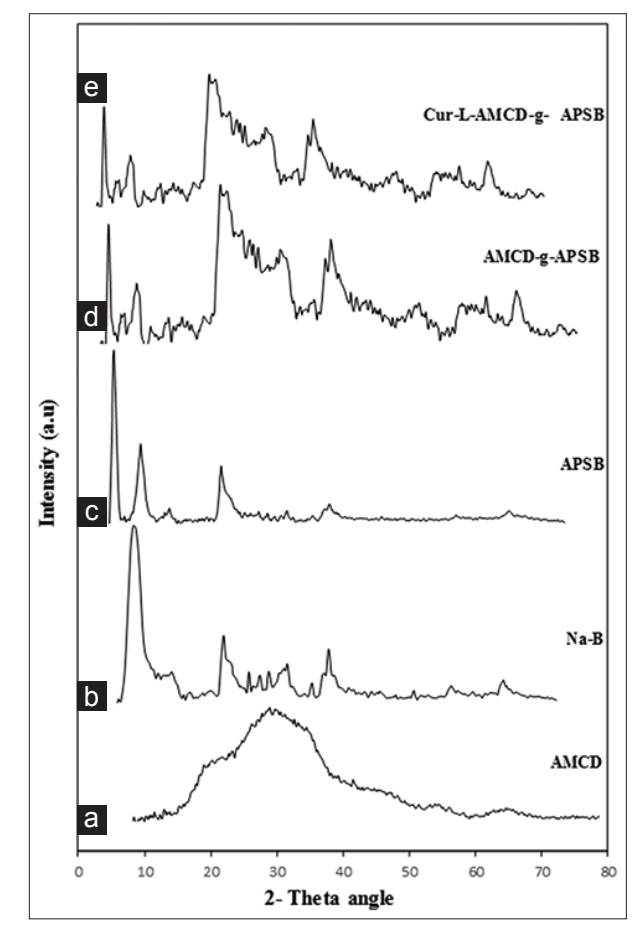

Fig. 3: X-ray diffraction of (a) acrylamide $\beta$-cyclodextrin (AMCD) (b) sodium bentonite (c) 3-aminopropyltriethoxysilane bentonite (APSB) (d) AMCD-grafted-APSB (AMCD-g-APSB) (e) curcumin-LAMCD-g-APSB 


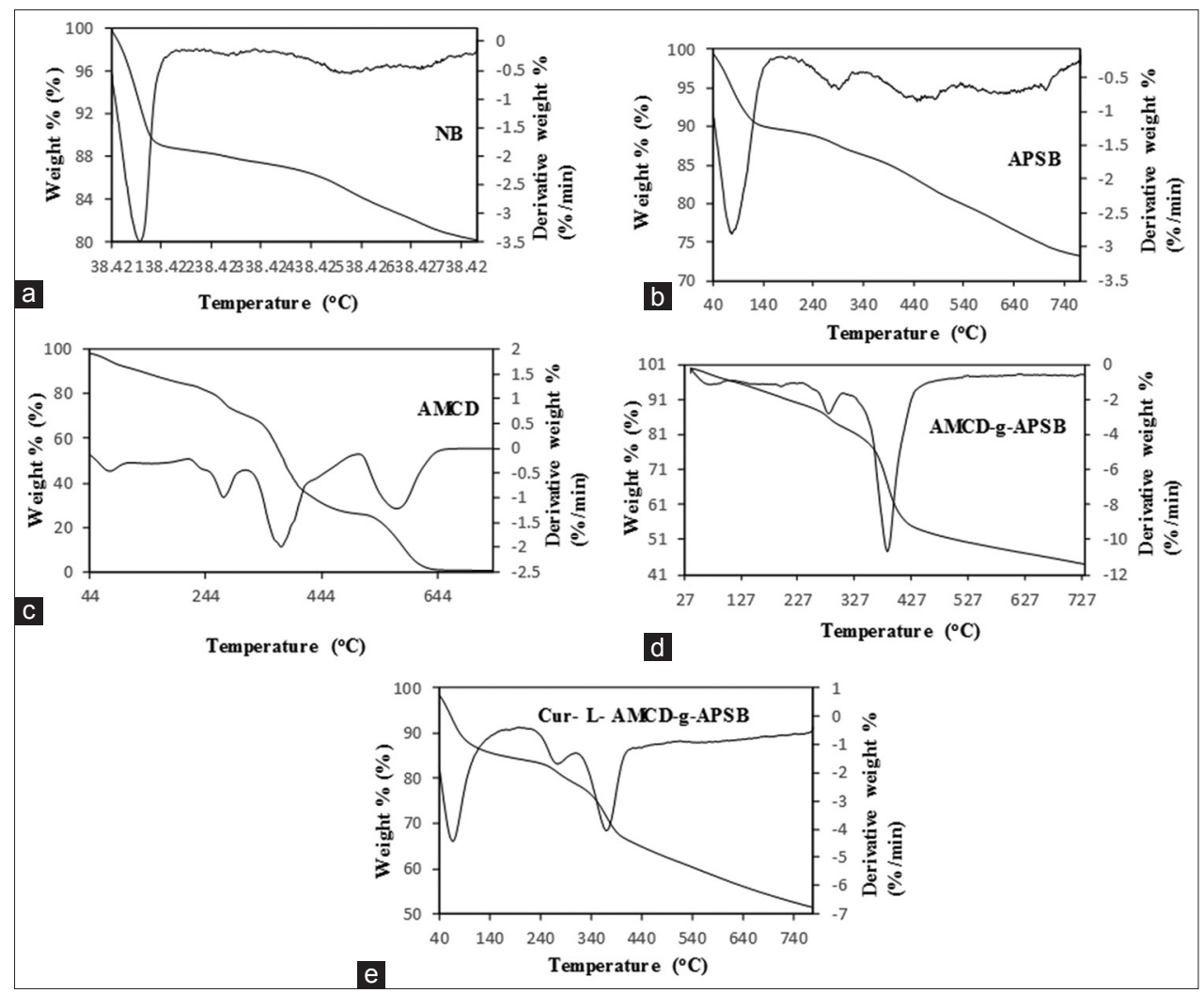

Fig. 4: Thermogravimetry-differential thermal analysis of (a) Sodium bentonite (b) 3-aminopropyltriethoxysilane bentonite (APSB) (c) acrylamide $\beta$-cyclodextrin (AMCD) (d) AMCD-grafted-APSB (AMCD-g-APSB), and (e) curcumin-L-AMCD-g-APSB

It showed four distinct weight loss events. The initial loss in weight below $100^{\circ} \mathrm{C}$ may be due to the loss of moisture from the composite. According to the literature, the weight loss observed for AMCD-g-APSB between 300 and $400^{\circ} \mathrm{C}$ can be attributed to the loss of intercalated APS molecules in the interlayer of NB. The TG and DTG curves of drug loaded composite showed three mass loss events. The initial weight loss was due to loss of moisture followed by two mass loss events which was due to the rupture of CUR moiety which was loaded onto DDS.

The SEM images of APSB, AMCD, AMCD-g-APSB, and CUR-loaded AMCDg-APSB were shown in Fig. 5. The NB has corn flake-like crystals with fluffy appearance revealing its extremely fine platy structure (figure not shown). Compared with the morphology of NB, the image of APSB appeared as individual clubbed particle. The surface of AMCD appeared rough with porous nature. These regular pores were connected to each other to form capillary channels. In general, the inorganic particles with polar lamellae and the hydrophobic units (3-aminopropyl triethoxy part in the silylating agent) undergo aggregation [17]. The surface of AMCD-g-APSB appeared to be irregular due to the presence of larger number of pore cavities. The surface of CUR-loaded AMCD-g-APSB seen to be as regular and homogeneous, due to the loading of CUR in the pore cavities.

The swelling profile of the composite at different $\mathrm{pH}$ and at different time intervals were shown in Fig. 6 . The swelling percentage of the composite strongly depends on both time and $\mathrm{pH}$ of the medium. For acidic $\mathrm{pH}$, the swelling percentage was lower than that in alkaline $\mathrm{pH}$ condition. The minimum swelling index was at $\mathrm{pH} 2$, and maximum was at $\mathrm{pH}$ 7.4. The swelling of the composite increases with $\mathrm{pH}$ and attains a maximum at $\mathrm{pH} 7.4$ and then gradually decreases. In high-pH medium (7.4), the hydrophilic groups(-OH) on the composite were getting ionised and the electrostatic repulsion between these negative charges led to the high swelling of the composite; however, in acidic medium, the absence of swelling caused the collapse of AMCD-g-APTSB. Similar results were reported by Anirudhan and Sandeep [31].

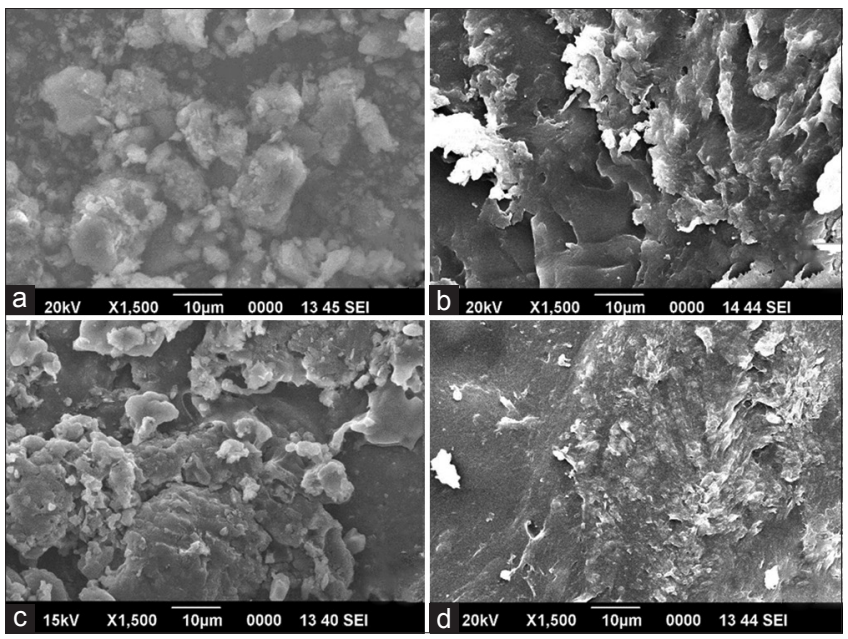

Fig. 5: Scanning electron microscope images of (a) grafted 3-aminopropyltriethoxysilane bentonite (APSB) (b) acrylamide $\beta$-cyclodextrin (AMCD) (c) AMCD-grafted-APSB (AMCD-gAPSB) and (d) curcumin-L-AMCD-g-APSB

The swelling process was found to be very fast and reached a maximum at $60 \mathrm{~min}$ after that it was slowly increased. The initial burst in swelling of the composite may due to the presence of the hydrophilic group on the surface of AMCD-g-APSB. After $60 \mathrm{~min}$, the decrease in rate of swelling can be attributed to the entering of water molecules in the internal boundary of the clay molecules which is initially not exposed to water molecules. Similar swelling $\mathrm{pH}$ dependencies were reported in the case of other composite hydrogels [32]

The physical and the chemical stability of CUR deeply depend on the $\mathrm{pH}$ [33] and light [21]. CUR undergoes photochemical degradation; 
therefore, all studies are carried out in amber-colored bottle. CUR was unstable at alkaline pH conditions. About $90 \%$ of CUR was degraded at the $\mathrm{pH}$ of 7.4 with in initial $15 \mathrm{~min}$. At the same time, the stability of CUR at acidic pH was very high, only $3.4 \%$ of the drug was degraded within $6 \mathrm{~h}$. The half-life period of CUR on the pH 3, 5, 6, 7, and 8 are $118.63,199.08,195.69,9.40,1.05$ and $14.04 \mathrm{~min}$ respectively. The high stability of CUR at acidic conditions may due to the presence of conjugated diene moiety. On increasing the $\mathrm{pH}$ (alkaline conditions), the $-\mathrm{OH}$ group at phenol gets easily deprotonated which causes the degradation [34]. The result of the present analysis on the stability study of CUR was compared with previous results and was found to be in good agreement [35]

The various formulation parameters in the synthesis of the composite were given in Table 2. The percentage of encapsulation was increased with increase in amount of AMCD. After attaining an optimum value of $2.5 \mathrm{~g}$, the encapsulation efficiency and the swelling percentage is decreased. This can be explained by the fact that with increasing the amount of AMCD, the diffusion of the drug molecules into the internal pore cavities of the clay gets decreased. The encapsulation efficiency also depends on the cross-linking agent. The optimum amount of cross-linking agent is found to be $0.5 \mathrm{~g}$. On increasing the amount of cross linker over the optimum value of $0.5 \mathrm{~g}$, the encapsulation capacity of the composite is getting decreased. This may due to compound formation of EGDMA itself with the composite and the composite becomes more rigid and the pore volume gets decreased [36].

The encapsulation study of CUR onto the composite AMCD-g-APSB was carried out at different $\mathrm{pH}$ conditions from 2 to 7. For comparison, the drug encapsulation study of the monomer unit of the composite (APSB) was also carried out. In the case of composite, the drug encapsulation was occurring maximum $(96.5 \%)$ at a $\mathrm{pH}$ of 3 . Whereas, the encapsulation of drug onto APSB at the same $\mathrm{pH}$ of 3 was only $81 \%$. The encapsulation study of AMCD-g-APSB and APSB at different $\mathrm{pH}$ conditions were represented in Fig. 7. In the case of APSB, there was a weak interaction between the $-\mathrm{NH}_{2}$ group present in the functionalized bentonite and the phenolic - $\mathrm{OH}$ group present in the CUR. With increase in the $-\mathrm{NH}_{2}$ functionalization on the clay surface, the encapsulation efficiency increases. The higher efficiency of AMCD-g-APSB compared to APSB is due to the weak interaction of CUR molecules with cone such as cavities of $\beta$-CD apart from interlayer cavities of clay. Moreover, the AMCD is behaving as a gate keeper which may regulate the entering and release of the drug molecules in the composite. The encapsulation efficiency of the composite depends on the amount of the monomers, cross-linking agent and also the $\mathrm{pH}$ of the medium. Acrylamido-2methylpropane sulfonic acid grafted $\mathrm{N}$-maleoylchitosan intercalated montmorillonite showed encapsulation efficiency of 94\% [31] whereas alginate/chitosan-coated mesoporous silica-based nanocarriers showed a value of $85.7 \%$ [36]. The AMCD-g-APSB (present study) showed higher encapsulation efficiency of $96.1 \%$ compared with other mesoporous silica materials. Therefore, it can be concluded that the prepared composite hydrogel is effective for the controlled and targeted delivery of therapeutics.
In-vitro release analysis

The controlled release study was carried out at different $\mathrm{pH}$ of 2.4, 6 , and 7.4 at the body temperature condition of $37^{\circ} \mathrm{C}$ was shown in Fig. 8. The maximum release of drug was seen at $\mathrm{pH}$. About $78.5 \%$ of drug was released within $48 \mathrm{~h}$ at $\mathrm{pH}$ 6.0. About $20 \%$ of the drug was released slowly within initial $10 \mathrm{~h}$. After that, there was a controlled release of the drug. At the $\mathrm{pH}$ of 2.4 , release of drug was comparably less, about $25.6 \%$ of drug was released within 48 h. Similarly, the release percentage $(38.1 \%)$ of drug at $\mathrm{pH} 7.4$ was also relatively small. The release of drug is related with the swelling index of the polymer. The maximum swelling of the polymer among three different $\mathrm{pH}$ are $7.4>6>2.4$. However, the release of drug is in the following order of $6>7.4>2.4$. This may due to the fact that the CUR is unstable at $\mathrm{pH} 7.4$.

The release study was also done for the monomer unit APSB, under the same procedure as carried out for AMCD-g-APSB. For APSB, the drug release was maximum at the $\mathrm{pH} 6(41.2 \%)$ and also shows a minimum
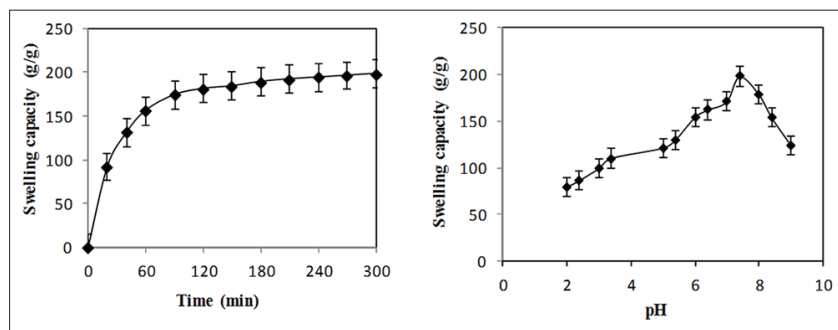

Fig. 6: Swelling study of the composite acrylamide $\beta$-cyclodextring-grafted 3-aminopropyltriethoxysilane bentonite at different time intervals and at different $\mathrm{pH}$ (triplicates for each sample were analyzed and each datum point represents the mean value \pm standard deviation; $n=3$ )

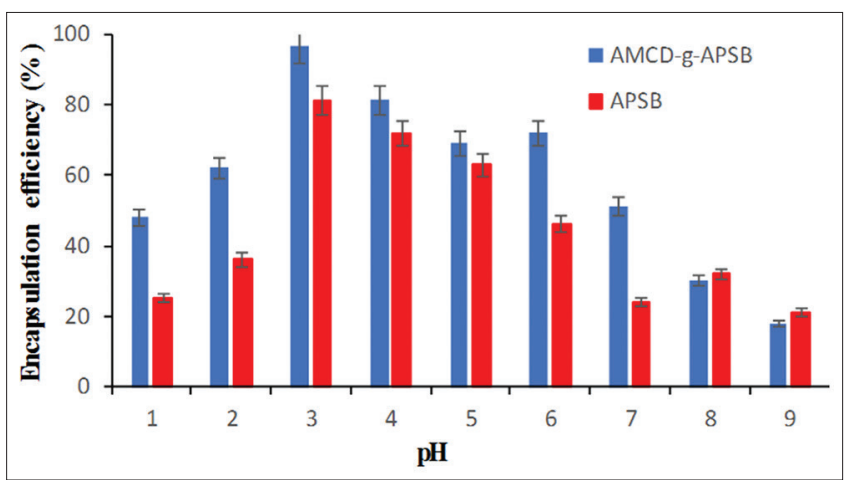

Fig. 7: Percentage of encapsulation efficiency of the acrylamide $\beta$-cyclodextrin-g-grafted 3-aminopropyltriethoxysilane bentonite (APSB) and APSB as a function of $\mathrm{pH}$ (triplicates for each sample were analyzed and each datum point represents the mean value \pm standard deviation; $n=3$ )

Table 2: Formulation parameters used in the synthesis of AMCD-g-APSB composite

\begin{tabular}{|c|c|c|c|c|c|}
\hline Sample code & APSB/g & $\mathrm{AMCD} / \mathrm{g}$ & Cross linking agent/g & Swelling \% of the composite $(\mathrm{g} / \mathrm{g})$ & Encapsulation efficiency (\%) \\
\hline A1 & 5 & 0.5 & 0.5 & $92 \pm 1.0$ & $49 \pm 028$ \\
\hline $\mathrm{A} 2$ & 5 & 1.0 & 0.5 & $109 \pm 0.5$ & $52 \pm 0.86$ \\
\hline A3 & 5 & 1.5 & 0.5 & $124 \pm 1.5$ & $60 \pm 0.57$ \\
\hline A4 & 5 & 2.0 & 0.5 & 1311.3 & $63 \pm 0.28$ \\
\hline A5 & 5 & 2.5 & 0.5 & $200 \pm 1.3$ & $96.1 \pm 2.0$ \\
\hline A6 & 5 & 5.0 & 0.5 & $86 \pm 0.57$ & $45 \pm 2.1$ \\
\hline A7 & 5 & 2.5 & 1.0 & $99 \pm 1.0$ & $50.5 \pm 1.7$ \\
\hline A9 & 5 & 2.5 & 0.5 & $200 \pm 1.3$ & $96.1 \pm 2.0$ \\
\hline A10 & 5 & 2.5 & 0.25 & $162 \pm 1.9$ & $81 \pm 2.0$ \\
\hline
\end{tabular}

All the results are expressed as \pm SD. SD: Standard deviation, AMCD-g-APSB: $\beta$-cyclodextrin grafted 3-aminopropyltriethoxysilane bentonite 

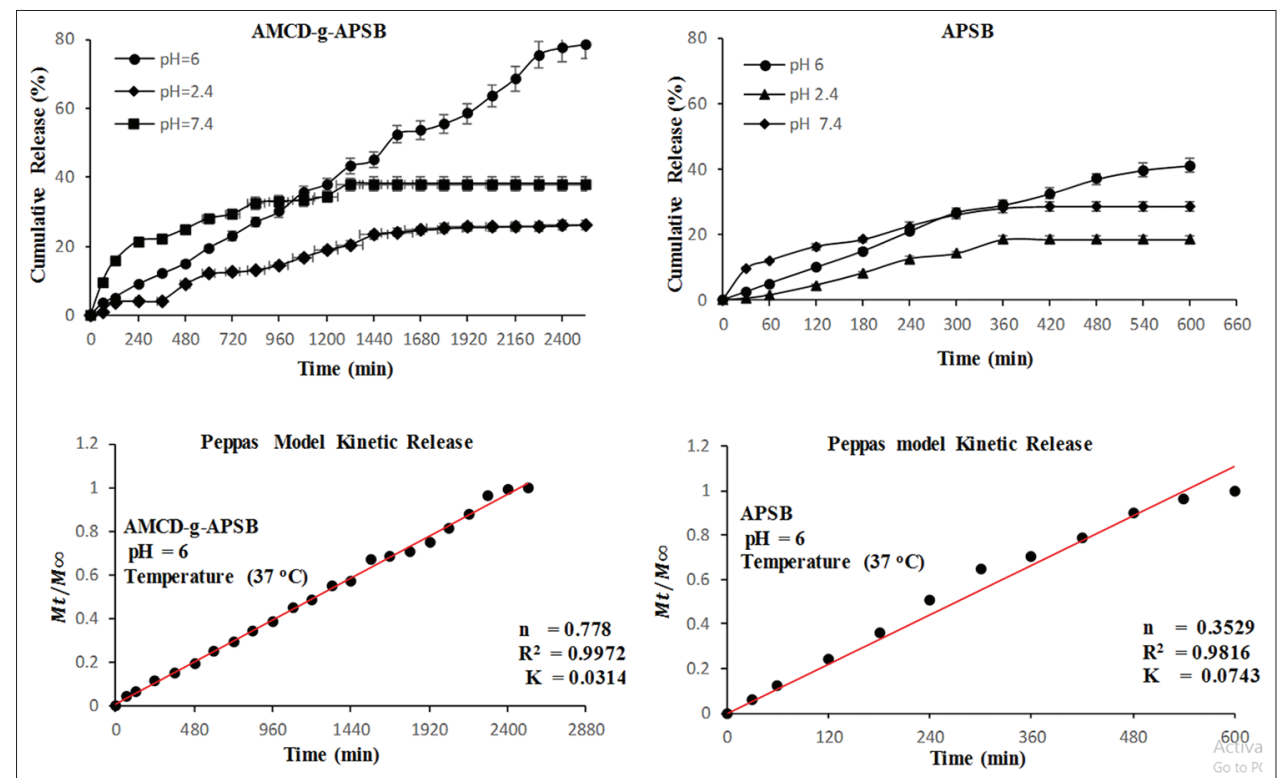

Fig. 8: In vitro release of curcumin from AMCD-grafted 3-aminopropyltriethoxysilane bentonite (APSB) and APSB and the corresponding Peppas kinetic model (triplicates for each sample were analyzed and each datum point represents the mean value \pm standard deviation; $\mathbf{n}=3$ )

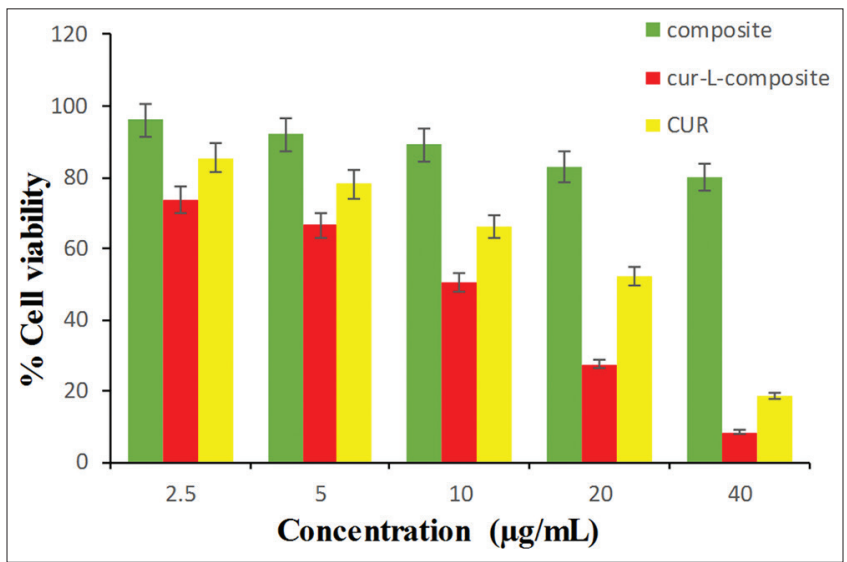

Fig. 9: In vitro cell viability of (a), the composite acrylamide $\beta$-cyclodextrin-g-grafted 3-aminopropyltriethoxysilane bentonite (b) curcumin (CUR)-L-composite, and (c) CUR (triplicates for each sample were analyzed and each datum point represents the mean value \pm standard deviation; $n=3$ )

at pH $2.4(18.5 \%)$ and for pH $7.4(28.6 \%)$. APSB is a good DDS and its efficiency can be improved by grafting process.

The $\mathrm{pH}$ of tumour cells is lower than the normal cells. The $\mathrm{pH}$ of tumor cells ranges from 5.0 to 6.0. In the present study, the maximum release of CUR is occurring at acidic $\mathrm{pH}$ of 6.0, so the developed biodegradable composite is better for the controlled release of CUR to the tumor cells.

The in-vitro drug release study was analyzed using Peppas kinetic equation (Fig. 8). In Peppas equation the value of $k$ gives an idea about the interaction of drug onto the DDS. Smaller the value of $\mathrm{k}$, weaker is the interaction between the drug and the DDS. The value of $n$ determines the release mechanism. The fitting of Peppas's kinetic model was analyzed on both AMCD-g-APSB and APSB at pH 6. The value of $n=0.778$ for AMCD-g-APSB showed that the release of drug follows non-Fickian mechanism. The release of drug depends both on the diffusion of drug and the swelling of the composite. The value of $\mathrm{k}$ for AMCD-g-APSB and APSB are 0.0314 and 0.0743 , smaller the value of $\mathrm{k}$ indicates the weaker interaction between the drug and the DDS [37].

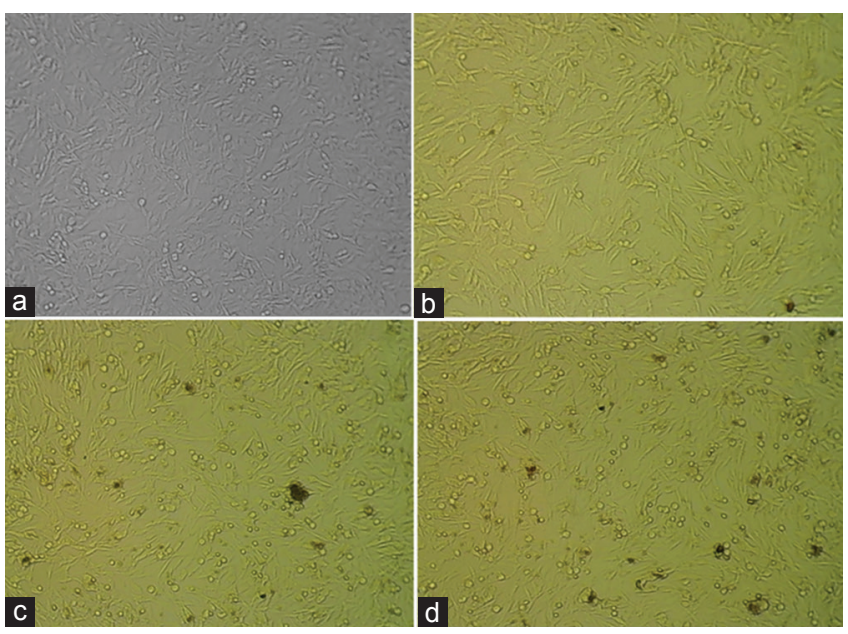

Fig. 10: The images of morphological changes in cells during the cell viability assay. (a) Controlled; (b) acrylamide $\beta$-cyclodextringrafted 3-aminopropyltriethoxysilane bentonite (AMCD-g-APSB

(c) Curcumin (CUR) and (d) CUR-L-AMCD-g-APSB at $5 \mu \mathrm{g} / \mathrm{ml}$ images with magnification $\times 20$ objectives

\section{Cell viability analysis}

The cell viability was analyzed by MTT method using U87MG cell line incubated to $48 \mathrm{~h}$ under variable concentration of $2.5-40.0 \mu \mathrm{g} / \mathrm{ml}$ as shown in Figs. 9 and 10. The cell viability of above $80 \%$ was considered as cytocompatible and nontoxic [38]. The percentage cell viability of the DDS (AMCD-g-APSB) was not below $80 \%$ even at higher concentration of $40.0 \mu \mathrm{g} / \mathrm{ml}$. The percentage cell viability decreases with increase in the concentration of DDS. In the case of the drug-loaded composite, the percentage of cell viability was decreased from $74 \%$ to $50.6 \%$ when the concentration of drug was increased from $5 \mu \mathrm{g} / \mathrm{ml}$ to $10 \mu \mathrm{g} / \mathrm{ml}$. This showed that the percentage of the cell toxicity was increased by the factor $22.4 \%$, when the concentration was doubled [39].

\section{CONCLUSION}

In the present work, we synthesized a novel drug delivery system by a green synthetic approach. The composite was characterized by FTIR, 
XRD, SEM, and differential scanning calorimetry. The swelling behavior of the composite was depending on the $\mathrm{pH}$, time, and composition of the components. The encapsulation efficiency was $\mathrm{pH}$ dependent. For a comparative study, the in vitro release study of APSB, one of the monomer units of this composite was also carried out. The maximum release of CUR was occurring at a $\mathrm{pH}$ 6. The CUR release from AMCD-gAPSB followed non-Fickian mechanism. The release of drug depends on both the diffusion and the swelling of the composite. The in vitro MTT assay on U87MG cell line confirmed the biocompatibility of the drug delivery system. The DDS was more potent for the controlled release of CUR to the tumor cells.

\section{ACKNOWLEDGMENTS}

The authors are expressing sincere gratitude to The Head, Department of Chemistry, Fatima Mata National College, Kollam, for providing laboratory facilities. The corresponding author thanks UGC, New Delhi, for financial assistance in the form of Minor Research Project (2324-MRP/15-16/KLKE015/UGC-SWRO). The authors sincerely acknowledging the services rendered by Indian Institute of Science, Bengaluru, for their assistance in the characterization of the samples.

\section{AUTHORS' CONTRIBUTIONS}

The work presented here was carried out with the collaboration between all authors.

\section{CONFLICT OF INTEREST}

There is no conflict of interest.

\section{REFERENCES}

1. Dhivya R, Ranjani J, Rajendhran J, Rajasekaran M, Annaraj J. pH responsive curcumin/ $\mathrm{ZnO}$ nanocomposite for drug delivery. Adv Mater Lett 2015;6:505-12.

2. Shome S, Talukdar AD, Choudhury MD, Bhattacharya MK, Upadhyaya H. Curcumin as potential therapeutic natural product: A nanobiotechnological perspective. J Pharm Pharmacol 2016;68:1481-500

3. Shanmugam MK, Rane G, Kanchi MM, Arfuso F, Chinnathambi A, Zayed ME, et al. The multifaceted role of curcumin in cancer prevention and treatment. Molecules 2015;20:2728-69.

4. Bandyopadhyay D. Farmer to pharmacist: Curcumin as an anti-invasive and antimetastatic agent for the treatment of cancer. Front Chem 2014;2:1-11.

5. Kim S, Stébé MJ, Blin JL, Pasc A. pH-controlled delivery of curcumin from a compartmentalized solid lipid nanoparticle@mesostructured silica matrix. J Mater Chem B 2014;2:7910-17.

6. Bharti C, Gulati N, Nagaich U, Pal A. Mesoporous silica nanoparticles in target drug delivery system: A review. Int J Pharm Investig 2015;5:124-33.

7. Carino IS, Pasqua L, Testa F, Aiello R, Puoci F, Iemma F, Picci N. Silicabased mesoporous materials as drug delivery system for methotrexate release. Drug Deliv 2007;14:491-5.

8. Li Y, Li N, Pan W, Yu Z, Yang L, Tang B. Hollow mesoporous silica nanoparticles with tunable structures for controlled drug delivery. ACS Appl Mater Interfaces 2017;9:2123-9.

9. Bouchoucha M, Côté M, Rene C, Fortin M, Kleitz F. Size-controlled functionalized mesoporous silica nanoparticles for tunable drug release and enhanced anti-tumoral activity size-controlled functionalized mesoporous silica nanoparticles for tunable drug release and enhanced anti-tumoral activity. ACS Chemmater 2016;28:4243-58

10. Thomas J, Kala D, Geroge A. Aminofunctionalised mesoporous silica nanoparticles loaded with 5-Flurouracil. Inter J Curr Adv Res 2017;6:2394-98.

11. Wei S, Hongping HE, Jianxi ZH, Peng Y, Yuehong MA, Xiaoliang L. Preparation and characterization of 3-aminopropyl-triethoxysilane grafted montmorillonite and acid-activated montmorillonite. Chinese 2009;54:265-71.

12. Sörensen MH, Samoshina Y, Claesson PM, Alberius P. Sustained release of ibuprofen from polyelectrolyte encapsulated mesoporous carriers. J Dispers Sci Technol 2009;30:892-902.
13. Khlibsuwan R, Siepmann F, Siepmann J, Pongjanyaku T. Chitosan-clay nanocomposite microparticles for controlled drug delivery: Effects of the MAS content and TPP crosslinking. J Drug Deliv Sci Technol 2017;40:1-10.

14. Mandal S, Patil VS, Mayadevi S. Alginate and hydrotalcite-like anionic clay composite systems: Synthesis, characterization and application studies. Microporous Mesoporous Mater 2012;30:892-902.

15. Sehgal P, Sharma M, Larsen KL, Wimmer R, Daniel E, Doe H. Influence of $\beta$ cyclodextrin on the mixed micellization process of sodium dodecyl sulfate and sodium lauroyl sarcosine and formation of inclusion complexes. J Disper Sci Technol 2008;29:128-33.

16. Ravichandran S, Karthikeyan E. Microwave synthesis-a potential tool for green chemistry. Inter J Chem Tech Res 2011;3:466-70.

17. Anirudhan TS, Gopal SS, Sandeep S. Synthesis and characterization of montmorillonite/ $\mathrm{N}$-(carboxyacyl) chitosan coated magnetic particle nanocomposites for controlled delivery of paracetamol. Appl Clay Sci 2014;88:151-8.

18. Reddy BH, Rauta RP, Venkatalakshimi V, Sreenivasa S. Synthesis and characterization of novel SA-PA-LSA/C-30B/AG nanocomposite for swelling, antibacterial, drug delivery, and anticancer application. Asian J Pharm Clin Res 2018;11:329-30.

19. Jain S, Datta M. Montmorillonite-alginate microspheres as a delivery vehicle for oral extended release of venlafaxine hydrochloride. J Drug Deliv Sci Technol 2016;33:149-56.

20. Ainurofiq A, Nurcahyo I, Yulianto R. Preparation, characterization and formulation of nanocomposite matrix Na-montmorillonite intercalated medium molecular weight chitosan for theophylline sustained rrelease tablet. Int J Pharm Pharm Sci 2014;6:131-7.

21. Bertuoli PT, Piazza D, Scienza LC, Zattera AJ. Preparation and characterization of montmorillonite modified with 3-aminopropyltriethoxysilane. Appl Clay Sci 2014;87:46-51.

22. Soppirnath KS, Aminabhavi TM. Water transport and drug release study from cross-linked polyacrylamide grafted guar gum hydrogel microspheres for the controlled release application. Eur J Pharm Biopharm 2002;53:87-98.

23. Kaity S, Isaac J, Kumar PM, Bose A, Wong TW, Ghosh A. Microwave assisted synthesis of acrylamide grafted locust bean gum and its application in drug delivery. Carbohydr Polym 2013;98:1083-94.

24. Vijan V, Kaity S, Biswas S, Isaac J, Ghosh A. Microwave assisted synthesis and characterization of acrylamide grafted gellan, application in drug delivery. Carbohydr Polym 2012;90:496-506.

25. Gunathilake TM, Ching YC, Chuah $\mathrm{CH}$. Enhancement of curcumin bioavailability using nanocellulose reinforced chitosan hydrogel. Polymers 2017;9:1-19.

26. Liu Y, Li Y, Li XM, He T. Kinetics of (3-aminopropyl)triethoxylsilane (aptes) silanization of superparamagnetic iron oxide nanoparticles. Langmuir 2013;29:15275-82

27. Su L, Tao Q, He H, Zhu J, Yuan P. Locking effect: A novel insight in the silylation of montmorillonite surfaces. Mater Chem Phys 2012;136:292-5.

28. Palanikumar L, Choi ES, Cheon JY, Joo SH, Ryu JH. Noncovalent polymer-gatekeeper in mesoporous silica nanoparticles as a targeted drug delivery platform. Adv Funct Mater 2015;25:957-65.

29. Hu C, Yu L, Zheng Z, Wang J, Liu Y, Jiang Y, et al. Tannin as a gatekeeper of $\mathrm{pH}$-responsive mesoporous silica nanoparticles for drug delivery. RSC Adv 2015;5:85436-41.

30. Sun R, Wang W, Wen Y, Zhang X. Recent advance on mesoporous silica nanoparticles-based controlled release system: Intelligent switches open up new horizon. Nanomaterials 2015;5:2019-53.

31. Anirudhan TS, Sandeep S. Synthesis and characterization of a novel $\mathrm{pH}$-controllable composite hydrogel for anticancer drug delivery. New J Chem 2011;35:2869-76.

32. Pourjavadi A, Hosseinzadeh H, Mazidi R. Synthesis and swelling behaviour of crosslinked kC-g-AMPS superabsorbent hydrogel with antisalt and $\mathrm{pH}$ responsiveness properties. J Appl Poly Sci 2005;98:255-63.

33. Shela TP, Mandowara VK, Gupta DG, Patel SV. Formulation of curcuminoid loaded solid lipid nanoparticles inorder to improve oral bioavailability. Int J Pharm Pharm Sci 2015;7:278-82.

34. Wang YJ, Pan MH, Cheng AL, Lin LI, Ho YS, Hsieh CY, et al. Stability of curcumin in buffer solutions and characterization of its degradation products. J Pharm Biomed Anal 1997;15:1867-76.

35. Khurana A, Ho CT. High-performance liquid chromatographic analysis of curcuminoids and their photo-oxidative decomposition compounds in Curcuma longa L. J Liq Chromatogr 1998;11:2295-304.

36. Feng F, Nie W, He C, Zhou X, Chen L, Qiu K, et al. Effect of pH- 
responsive alginate/chitosan multilayers coating on delivery efficiency, cellular uptake and biodistribution of mesoporous silica nanoparticles based nanocarriers. Appl Mater Interfaces 2014;5:8447-60.

37. Anirudhan TS, Binusreejayan, Jayan PP. Development of functionalized chitosan-coated carboxylated mesoporous silica: A dual drug carrier. Des Monomers Polym 2016;19:381-93.

38. Anirudhan TS, Nair SS, Sekhar V. Deposition of gold-cellulose hybrid nanofiller on a polyelectrolyte membrane constructed using guar gum and poly(vinyl alcohol) for transdermal drug delivery. J Memb Sci 2017;539:344-57.

39. Liu Y, Pan J, Feng SS. Nanoparticles of lipid monolayer shell and biodegradable polymer core for controlled release of paclitaxel: Effects of surfactants on particles size, characteristics and in vitro performance. Int J Pharm 2010;395:243-50. 